\title{
Dentistry - art or science? Has the clinical freedom of the dental professional been undermined by guidelines, authoritative guidance and expert opinion?
}

\author{
Robert L. Caplin*1
}

\section{Key points}

Dentistry is more of an art than a science, more subjective than objective, resulting in wide variations in clinical judgements and interventions between dental practitioners.
The validity of published papers is questionable and hence guidelines, authoritative guidance and expert opinion based on such publications should be regarded with caution.
The nature of healthcare means that concepts such as judgement, opinion and uncertainty are with us all the time and, therefore, we should rely not just on guidelines and expert opinions but on experience too and not be overly influenced by the way that these are interpreted by the regulatory bodies.

\begin{abstract}
The General Dental Council (GDC) requires dental practitioners to provide good-quality care based on current evidence and authoritative guidance. However, this leaves the dental practitioner in a sort of limbo as good quality is an ill-defined term allowing its precise meaning to be open to interpretation. This article sets out to demonstrate that the practice of dentistry is very much more of an art than a science and, as such, relies on individual skill and judgement. It will also show that the 'value' of current evidence as determined by published papers and authoritative guidance is questionable and should not be regarded by dental practitioners as the 'rule'. The interaction between a dentist and a patient essentially consists of clinical decision-making and the implementation of that decision and, therefore, it is essential to understand the nature of decision-making and the context in which implementation takes place. Practitioners should exercise their clinical judgement, putting the interests of the patient first and not feel constrained by the threat of sanctions from the GDC or other regulatory bodies.
\end{abstract}

\section{Introduction}

Dentistry is 'the art or profession of a dentist.' And what is a profession? 'An occupation whose core element is work based upon the mastery of a complex body of knowledge and skills. It is a vocation in which knowledge of some department of science or learning or the practice of an art founded upon it is used in the service of others. Its members are governed by codes of ethics and profess a commitment to competence, integrity and morality, altruism, and the promotion of the public good within their domain. These commitments form the basis of a social contract between a profession

'Senior Teaching Fellow and General Dental Practitioner, Faculty of Dentistry and Oral and Craniofacial Sciences, King's College London, Guy's Hospital, London SE1 9RT, UK *Correspondence to: Robert Caplin Email address: bob@rlcaplin.com

Refereed Paper.

Accepted 16 October 2020

https://doi.org/10.1038/s41415-021-2726-4 and society, which in return grants the profession a monopoly over the use of its knowledge base, the right to considerable autonomy in practice and the privilege of selfregulation. Professions and their members are accountable to those served and to society. ${ }^{2}$

\section{Art or science?}

How much of a dental professional's work can be considered to be art and subjective, and how much can be considered to be science and objective? The interaction between a dentist and a patient essentially consists of clinical decision-making and the implementation of that decision. Clinical decision-making, by its nature, can be considered as professional artistry. ${ }^{3}$ Whereas some areas are underpinned by science and an evidence base (for example, properties of dental materials, caries management), many are not. Furthermore, the efficacy of treatments depends to a large degree on the skill of the operator, where skill is practical knowledge in combination with ability, cleverness and expertness. ${ }^{4}$ There isn't a probe that we can put on a particular tooth that will tell us what to do. Fill this one. Watch this one. Repair this filling. Put a post in that tooth. Extract this tooth. These are all decisions that are ultimately subjective, and therefore, the reason for the variations that we see in care plans between different dentists and even between the same dentist on different days and at different times. This very much leads to the conclusion that dentistry is more of an art than a science.

\section{Accountability to those served and to society}

If the practice of dentistry is grounded in subjectivity and the ensuing individualism, then it is only logical and reasonable that for the protection of society some degree of supervision and guidance be given to prevent extremes of treatment and the 
abuse of patients. Accountability to those served and society (as per the definition of a professional above); that is, the governance of dentistry in the United Kingdom (UK), is administered by the General Dental Council (GDC) whose work is defined and governed by the Dentists Act 1984, which sets out the following objectives: ${ }^{5}$

- To protect, promote and maintain the health, safety and wellbeing of the public

- To promote and maintain confidence in the dental profession

- To promote and maintain proper professional standards and conduct for members of those professions.

Under the Act, the GDC has five specific responsibilities that it has the powers to enact:

- Grant registration only to those dental professionals who meet our requirements on education and training, health and good character. Only those who are registered with us can practise dentistry in the UK

- Set standards for providers of dental education and training in the UK

- Set standards of conduct, performance and ethics for the dental team

- Investigate complaints against dental professionals and where appropriate take action through our fitness to practise process

- Require dental professionals to keep their skills up to date through our continuing professional development requirements.

In meeting its specific responsibility to set standards of conduct, performance and ethics, the GDC in its publication Standards for the dental team ${ }^{6}$ states in Section 7.1: 'Provide good-quality care based on current evidence and authoritative guidance'.
However, this leaves the dental practitioner in a sort of limbo as good quality and authoritative guidance are ill-defined, allowing their precise meanings to be open to interpretation. And in reality, quality is not an absolute but a scale, a range, as recognised by The Faculty of General Dental Practice (UK) (FGDP[UK]) in its publication Standards in Dentistry, which recognises three levels of care: aspirational, basic and conditional. ${ }^{7}$

Despite the lack of clarity, it is the interpretation of the GDC which decides the fate of a practitioner. Failure in the application of, or deviation from, guidelines, expert opinion or authoritative guidance can result in the professional concerned being called to a fitness to practise hearing before the Professional Conduct Committee of the GDC with its ability to impose sanctions. Importantly, if a practitioner is to be held to account for his/her actions, then it becomes imperative to understand how, or if, good quality can be determined and who or what comprise authoritative guidance (Fig. 1).

\section{Good quality}

Good as defined by the Oxford English Dictionary ${ }^{8}$ is 'implying that the thing described is of high or satisfactory quality, suitable for some purpose, or worthy of approval' and quality is 'a special feature or characteristic.'

\begin{tabular}{l|l|l|l|}
\multicolumn{2}{|c}{ Table 1} & Quality rating criteria for film captured images ${ }^{10}$ \\
\hline Rating & Quality & Basis \\
\hline 1 & Excellent & No errors of patient preparation, exposure, positioning, processing or film handling \\
\hline 2 & $\begin{array}{l}\text { Diagnostically } \\
\text { acceptable }\end{array}$ & $\begin{array}{l}\text { Some errors of patient preparation, exposure, positioning, processing or film } \\
\text { handling but the image is still of diagnostic value }\end{array}$ \\
\hline 3 & Unacceptable & $\begin{array}{l}\text { Errors of patient preparation, exposure, positioning, processing or film handling } \\
\text { and the image is of no diagnostic value }\end{array}$ \\
\hline
\end{tabular}

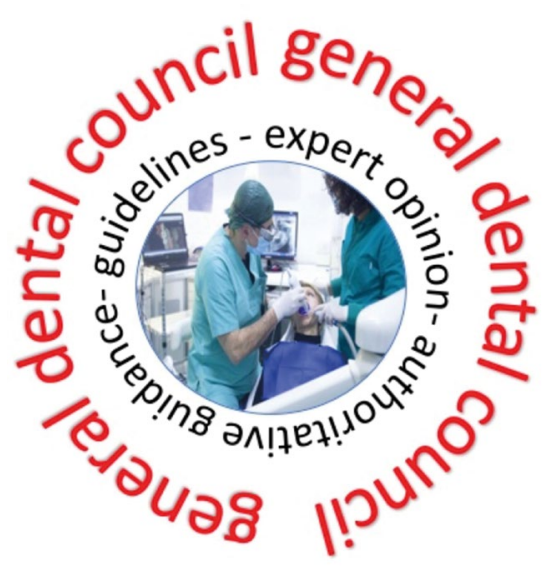

Fig. 1 Relationship between the dentistpatient interaction and clinical guidelines, expert opinion, authoritative guidance and the General Dental Council

Even here, we have the possibility of variable interpretations, although attempts have been made to establish levels of quality in clinical situations. The concept of quality can readily be applied to radiographs (Table 1) and it can also be applied to restorations (Table 2).

However, as any clinician will know, whereas the alpha level is the aspirational and desirable level of care for a restoration, it is not always achievable for a variety of reasons and so context becomes an important consideration when judging the treatment outcome. It should

\section{Table 2 Criteria for the evaluation of dental restorative materials ${ }^{11}$}

\begin{tabular}{|c|c|c|c|}
\hline Clinical characteristic & Alpha & Bravo & Charlie \\
\hline $\begin{array}{l}\text { Marginal adaptation } \\
\text { (MA) }\end{array}$ & $\begin{array}{l}\text { Explorer does not catch or has one way catch when } \\
\text { drawn across the restoration/tooth interface }\end{array}$ & $\begin{array}{l}\text { Explorer falls into crevice when drawn } \\
\text { across the tooth/restoration interface }\end{array}$ & Dentine or base is exposed \\
\hline Anatomic form $(A)$ & $\begin{array}{l}\text { The general contour of restoration follows the } \\
\text { contour of the tooth }\end{array}$ & $\begin{array}{l}\text { The general contour of the restoration } \\
\text { does not follow the contour of the tooth }\end{array}$ & The restoration has an overhang \\
\hline Surface roughness $(R)$ & $\begin{array}{l}\text { The surface of the restoration has no surface } \\
\text { defects }\end{array}$ & $\begin{array}{l}\text { The surface of the restoration has } \\
\text { minimal defects }\end{array}$ & $\begin{array}{l}\text { The surface of the restoration has severe } \\
\text { surface defects }\end{array}$ \\
\hline Marginal staining (MS) & $\begin{array}{l}\text { There is no discolouration between the } \\
\text { restoration and the tooth }\end{array}$ & $\begin{array}{l}\text { There is discolouration on less than half } \\
\text { of the circumferential margin }\end{array}$ & $\begin{array}{l}\text { There is discolouration on more than half of } \\
\text { the circumferential margin }\end{array}$ \\
\hline Occlusal contact (C) & Normal & Light & None \\
\hline Secondary caries (CS) & There is no clinical diagnosis of caries & $\mathrm{N} / \mathrm{A}$ & There is clinical diagnosis of caries \\
\hline Luster (L) & $\begin{array}{l}\text { The restoration surface is shiny and has an } \\
\text { enamel-like translucent surface }\end{array}$ & $\begin{array}{l}\text { The restoration surface is dull and } \\
\text { somewhat opaque }\end{array}$ & $\begin{array}{l}\text { The restoration surface is distinctly dull and } \\
\text { opaque and is aesthetically displeasing }\end{array}$ \\
\hline
\end{tabular}


not be considered as a binary exercise; that is, the restoration is either satisfactory or unsatisfactory, because the context of treatment is paramount in assessing the standard of care.
Think of a tooth that is in need of attention. If this tooth was taken from the mouth and a decision had to be made on the best way to bring this tooth back to health, there may be
Fig. 2 Factors affecting clinical decision-making in restorative dentistry

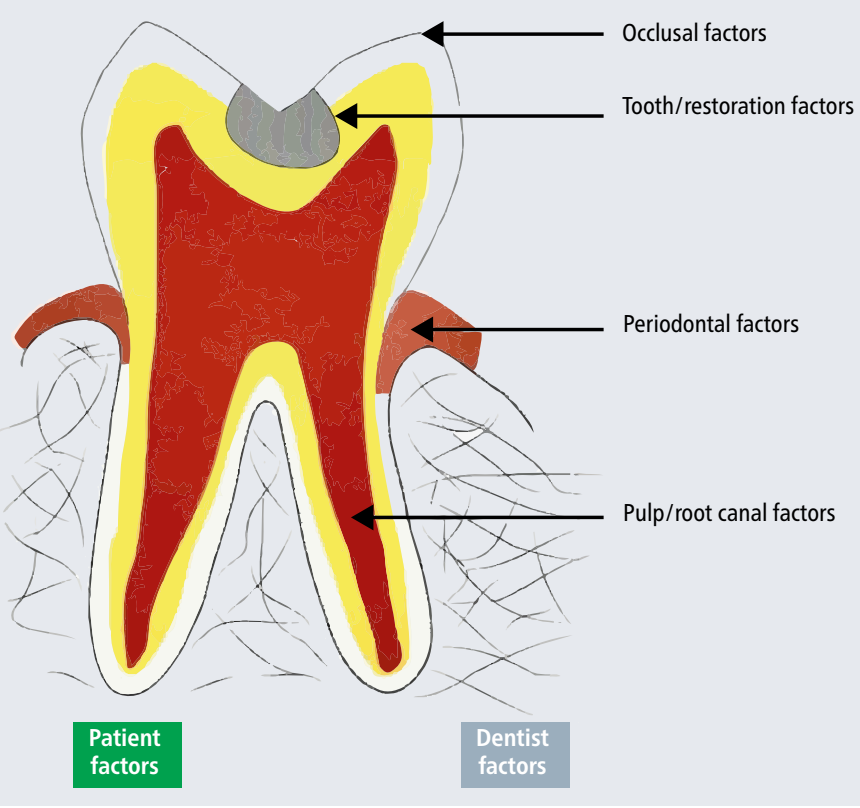

Table 3 Two views of professional practice, reproduced with permission from D. Fish, Quality mentoring for student teachers: a principled approach to practice, pp 43, London: David Fulton Publishers, $1995^{3}$

\begin{tabular}{l|l}
\hline The technical/rational view & The professional/artistry view \\
\hline Follows rules, laws, routines and prescriptions & Starts where rules fade, sees patterns, frameworks \\
\hline Uses diagnosis, analysis & Uses interpretations/appreciation \\
\hline Wants efficient systems & Wants creativity and room to be wrong \\
\hline Sees knowledge as graspable, permanent & Knowledge is temporary, dynamic, problematic \\
\hline Theory is applied to practice & Theory emerges from practice \\
\hline Visible performance is central & There is more to it than surface features \\
\hline $\begin{array}{l}\text { Setting out and testing for basic } \\
\text { competency is vital }\end{array}$ & There is more to it than the sum of the parts \\
\hline Technical expertise is all & Professional judgement counts \\
\hline $\begin{array}{l}\text { Sees professional activities as capable of } \\
\text { being mastered }\end{array}$ & Sees mystery at the heart of professional activities \\
\hline Emphasises the known & Embraces uncertainty \\
\hline Standards must be fixed & That which is most easily fixed and measurable is also often trivial \\
\hline $\begin{array}{l}\text { Standards are measurable and must be } \\
\text { controlled }\end{array}$ & \\
\hline $\begin{array}{l}\text { Emphasises assessment, inspection, } \\
\text { accreditation }\end{array}$ & Emphasises investigation, reflection, deliberation \\
\hline Change must be managed from outside & Professionals can develop from inside \\
\hline $\begin{array}{l}\text { Quality is really about the quantity of that } \\
\text { which is easily measurable }\end{array}$ & $\begin{array}{l}\text { Quality comes from deepening insight into one's values, } \\
\text { priorities, actions }\end{array}$ \\
\hline Technical accountability & Professionals answerability \\
\hline This is training & This is education \\
\hline It takes the instrumental view & It sees education as intrinsically worthwhile \\
\hline &
\end{tabular}

the ideal solution. Now, if that tooth is replaced back into the mouth, the solution to bring this back to health; that is, 'what should be done here?', may well be very different because a wide variety of factors have to be taken into account (Fig. 2). ${ }^{12}$

\section{Clinical decision-making/ judgement}

If a practitioner's clinical decision-making is to be called into question, it is important to understand precisely what clinical decisionmaking is. Decision-making is a broad term that applies to the process of making a choice between options as to a course of action. Clinical decision-making/reasoning is the process used to make a judgement about what to believe and what to do about the symptoms and signs that a patient presents with to enable a diagnosis to be made and treatment options considered. Facione and Facione ${ }^{13}$ considered clinical reasoning as a process 'that in order to arrive at a judgement about what to believe and what to do, a clinician should consider the unique character of the symptoms (evidence) in view of the patient's current health and life circumstances (context), using the knowledge and skills acquired over the course of the health sciences training and practice (methods, conceptualisations), anticipate the likely effects of a chosen treatment action (consideration of evidence and criteria) and finally monitor the eventual consequences of delivered care (evidence and criteria)'. Trowbridge et al. ${ }^{14}$ extend this by seeing clinical reasoning not only as a conscious process but with the healthcare worker also interacting with the patient and the environment at an unconscious level. Critical thinking is defined by the American Philosophical Society ${ }^{15}$ as the process of purposeful, self-regulatory judgement which gives reasoned consideration to evidence, contexts, conceptualisations, methods and criteria, which shows how this process is integral to clinical reasoning and decision-making.

\section{Clinical decision-making - professional artistry or technical/ rational?}

There are two very different views in the approach to clinical decision-making which embrace the variables of opinion and expertise; the technical/rational approach and the professional/artistry approach whose differences are shown in Table 3. 
The technical/rational approach leans heavily on the 'theoretical' in that it relies on guidelines and best practice in the most common situations. These are provided by 'experts', who may often disagree among themselves and thus this approach divorces itself from the reality of a world in which patients do not fit into neat patterns of disease. This leads to the 'grey areas' that are in the real world and the technical/rational approach potentially, inevitably, forces the practitioner along treatment paths while his instinct and expertise may demand an alternative. Deviation from these pathways requires the clinician to fully justify such behaviour, which in practical terms will mean extensive additional entries in the patient's record. This trend seeks to embed within it certainty and hard evidence. The professional artistry is 'practical' in that it seeks solutions to problems as they are, not how they should be, and allows for more flexibility and thinking from the professional. It recognises and embraces uncertainty. Further support for the professional/artistry approach comes from Friedmann-Smith et al. ${ }^{16}$ and Stolper et al., ${ }^{17}$ who emphasise the role of gut feeling where gut feeling is used interchangeably with suspicion, instinct and intuition.

Fish et al. ${ }^{3}$ reject the technical/rational view of 'health care delivery' because it makes the following assumptions:

- That quality healthcare practice is achieved only through the strict adherence to well-thought-out (and evidence-based) guidelines and protocols

- That health professionals (especially junior ones, as lower status professionals) are not capable of making judgements (or should not be expected to)

- That professional judgements are dangerous departures from established procedures because they allow too much variability in situations that require to be controlled.

Furthermore, the technical/rational approach ignores the existence of the judgements that all health professionals take all the time and denies the importance of people making these judgements. The professional/ artistry approach should be viewed as the better approach because it recognises individual creativity and leads to professional growth. This approach empowers the professional to think rather than just rely on authoritative guidance and should be promoted for all dental professionals.

\section{What is authoritative guidance and how reliable is it?}

Authoritative guidance, guidelines and standards are usually issued by governmental organisations, colleges or professional bodies such as the GDC, Government Services, National Institute for Health and Care Excellence (NICE), Scottish Dental Clinical Effectiveness Programme (SDCEP), Faculty of Dental Surgery of the Royal College of Surgeons of England (FDS RCS) and Faculty of General Dental Practice (FGDP UK).

The FGDP(UK)'s Standards in Dentistry lists 14 clinical guidelines and seven non-clinical guidelines and uses the following definitions: 'Clinical guidelines are systematically developed statements to assist a practitioner and patient decisions about appropriate healthcare for specific clinical circumstances.' 'A standard is a definable measure against which existing structures processes or outcomes can be compared.' 7 According to NICE, ${ }^{18}$ 'a clinical guideline applies to all patients with a particular condition, but there will be times when the recommendations are not appropriate for a particular patient. Healthcare and other professionals are expected to take our clinical guidelines fully into account when exercising their professional judgement. However, the guidance does not override the responsibility of healthcare professionals and others to make decisions appropriate to the circumstances of each patient. These decisions should be made in consultation with, and with the agreement of, the patient and/or their guardian or carer. Healthcare professionals and others should record their reasons for not following clinical guideline recommendations'.

Clinical guidelines are based on the best available evidence and are produced to help healthcare professionals and patients make informed choices about appropriate healthcare. Guidelines do not replace the knowledge and skills of healthcare professionals - they complement clinical judgement with the primary objective of enhancing quality of care, and their development is facilitated by the availability of high-quality research. However, it is often in areas where the evidence is weak or conflicting that guidance for clinicians is most needed. When the scientific evidence needed to answer key clinical questions is either of poor quality, inconsistent or non-existent, recognised methods for developing consensus can be used by guideline developers to assist in the formulation of recommendations.
Definitions of guidelines leave some room for clinical and legal interpretation

These definitions of guidelines leave some room for clinical and legal interpretation, which is an area explored by Taylor, writing in the Journal of Legal Medicine: ${ }^{19}$ 'Clinical Practical Guidelines (CPGs) can be useful for physicians. In the best cases, guidelines represent a consensus opinion regarding a given clinical situation formed by a group of experts after careful analysis of relevant science and clinical literature. Unfortunately, guidelines require the same detailed scrutiny that practitioners are expected to apply to primary clinical research studies [...] However, the validity and relevance of guidelines for any given case will require the opinion of an expert. Opposing experts often will disagree. Furthermore, the possibility of significant bias in the development of CPGs should limit any blanket acceptance of guidelines as representing the standard of care [...] Therefore, CPGs should be admitted into evidence (in court cases) and considered along with primary science, customary practice, clinical experience, and expert opinion regarding the particular facts of each individual case, as the elements that define the standard of care. Nevertheless, CPGs considered alone and in isolation of the facts of the case do not represent the standard of care'.

Disagreement between experts is also highlighted in the acknowledgements section of the FGDP(UK)'s Standards in dentistry publication: ${ }^{6}$ 'In some cases we have had to resolve strongly-held but contradictory views held by consultees and peer reviewers'.

These disagreements and contradictory views are important because, should the occasion arise, a practitioner should be able to rely on a dissenting view to justify the action or decision that had been taken. On the basis that the panel constructing the guidelines or authoritative advice contained experts, the logical conclusion is that some members of these panels are practising outside the guidelines they disagreed with. It would, therefore, be beneficial if the membership of such panels or specialist groups was put in the public domain together with their position on the subject at hand.

NICE and Taylor raise very important issues, namely the role of opinion and expertise in a clinical situation or in the setting of standards and the reliability of published papers, guidelines and evidenced-based clinical practice. 


\section{The reliability of published papers}

One can assume that clinical guidelines and authoritative guidance arise from meetings of experts in their fields, each bringing their own expert opinion and interpretation of the published literature. But just how much can the published literature be relied on, and, as a consequence, how justifiable will be the recommendations of those meetings?

The quality of evidence in scientific studies can be given a visual representation in the form of the scientific evidence pyramid (Fig. 3), as drawn by J-F Roulet. ${ }^{20}$

The base of the triangle is long but it is weak in its quality. Similarly, the number of sources that form poor-quality evidence is higher than other types of study; that is, the number of sources is large like the base. The quality of the evidence increases as it moves towards the top of the pyramid, while the number of sources decreases. Just below the pinnacle is the systematic review. A systematic review is the collection and synthesis of high-quality evidence to a particular question. At the pinnacle is the meta-analyses, which is a statistical integration of quantitative results to provide an estimated value. In other words, it is the analysis of analyses. Meta-analyses, together with systematic reviews, form the highest quality of evidence in scientific studies.

\section{Cochrane reviews}

Cochrane reviews are systematic reviews of primary research in human healthcare and health policy, and are internationally recognised as the highest standard in evidencebased healthcare. They investigate the effects of interventions for prevention, treatment and rehabilitation. They also assess the accuracy of a diagnostic test for a given condition in a specific patient group and setting. They are published online in the Cochrane Library. Each systematic review searches for and summarises studies that answer a specific research question. So, it would be reasonable to assume that these expert committees giving authoritative guidelines were relying on the highest level of evidence. Unfortunately, this does not appear to be the case.

A search of Cochrane reviews related to restorative dentistry revealed 52 reviews of which 27 mentioned low-quality evidence and where no conclusion could be drawn as to the effectiveness or not of the proposed

\section{Fig. 3 The scientific evidence pyramid, reproduced with permission from J-F Roulet, How to} set up, conduct and report a scientific study, Stomatology Edu Journal, 201720

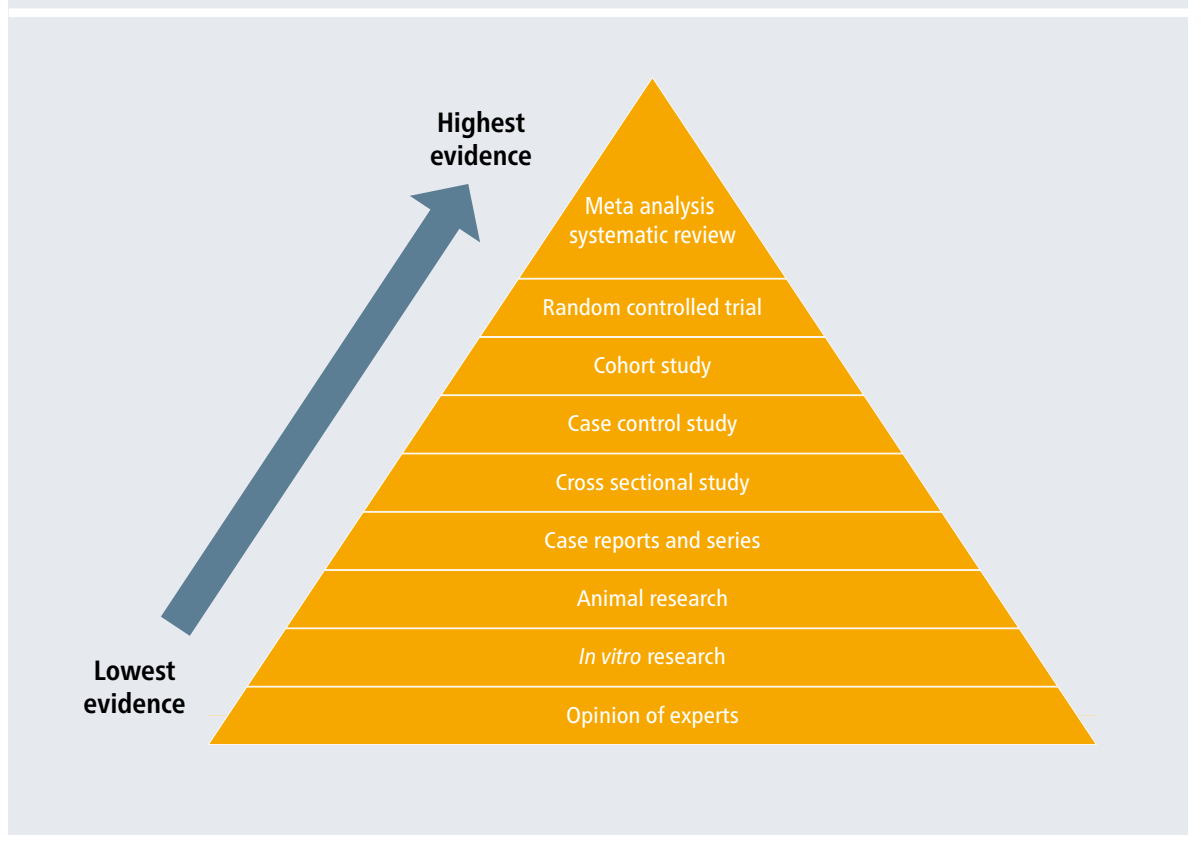

question. A typical example is an attempt by the Cochrane review to answer the question: 'single crowns or routine fillings for the restoration of root-filled teeth?'21 This review (an update of the original published in 2012) had been conducted to assess whether there is a difference in the effects of restoration of root-filled teeth (with or without post and core) by indirect restorations (commonly crowns, inlays, or onlays) compared to conventional filling materials placed directly into the tooth. The original electronic searches in 2012 retrieved 1,022 references to studies after de-duplication, out of which 1,016 were clearly ineligible and were eliminated. Full-text copies of the remaining six studies were subjected to further evaluation. Then, all but one of these studies were excluded. The updated searches to 26 March 2015 retrieved 279 references to studies, all of which were rejected after examination of title and abstract. What was the authors' conclusion? 'There is insufficient evidence to assess the effects of crowns compared to conventional fillings for the restoration of root-filled teeth. Until more evidence becomes available, clinicians should continue to base decisions about how to restore root-filled teeth on their own clinical experience, while taking into consideration the individual circumstances and preferences of their patients. From 1,022 papers originally identified in their literature search on this subject, eventually only one was considered to be useful. This, rather worryingly, tells us that much, if not most, of the published literature should be treated with caution and it is reasonable, therefore, to question their role in forming guidelines or recommendations.

\section{Most current published research findings are false}

There is support for this in the literature. According to Ioannides: ${ }^{22}$ 'There is increasing concern that most current published research findings are false. The probability that a research claim is true may depend on study power and bias, the number of other studies on the same question, and, importantly, the ratio of true to no relationships among the relationships probed in each scientific field. In this framework, a research finding is less likely to be true when the studies conducted in a field are smaller; effect sizes are smaller; there is a greater number and lesser preselection of tested relationships; there is greater flexibility in designs, definitions, outcomes, and analytical modes; there is greater financial and other interest and prejudice; and more teams are involved in a scientific field in cases of statistical significance. Simulations show that for most study designs and settings, it is more likely for a research claim to be false than true. Moreover, for many current scientific fields, claimed research findings often may be simply accurate measures of the prevailing bias. Published research findings are refuted 
sometimes by subsequent evidence, with ensuing confusion and disappointment. Refutation and controversy are seen across the range of research designs, from clinical trials and traditional epidemiological studies to the most modern molecular research. There is increasing concern that in modern research, false findings may be the majority, or even the vast majority, of published research claims. However, this should not be surprising. It can be proven that most claimed research findings are false.'

Support for this view comes from Moonesinghe et al.:23 'In summary, while we agree with Ioannidis that most research findings are false, we clearly demonstrate that replication of research findings enhances the positive predictive value of research findings being true'. Ritchie ${ }^{24}$ dedicates his book, Science Fictions, to fraud, bias, negligence and hype in science.

There has been a mantra in dentistry about the accuracy of clinical notes: 'if it was not written down it did not happen. ${ }^{25}$ However, this mantra could be turned on its head with regards to scientific papers - 'if it is written down (that is, published) it may have happened (but not necessarily in the way that it was reported!)'

\section{It seems like a good idea!}

How does a clinical procedure come to be the 'accepted' mode of treatment or a requirement? The answer to this seems to be that it 'seems like a good idea'. Bodies such as the GDC and Care Quality Commission (CQC) have stated in the past that it is a 'requirement', implying a statutory duty, to keep a note of batch numbers for local anaesthetics. Dental Protection advise that there is no legal or regulatory requirement to record the batch number of each local anaesthetic cartridge when providing dental treatment. ${ }^{26}$ They trace this 'requirement' to Richard Baker, who was Professor of Quality and Health Care in Leicester who said, following the Harold Shipman scandal, that: 'There is now confusion about who is responsible for keeping a check on doctors' use of controlled drugs such as Diamorphine, which Shipman used to kill his victims [...] batch numbers should be recorded in clinical records'. These remarks were intended for 'controlled' drugs but has been more freely interpreted by various bodies as being a 'requirement' for all drugs.
The $\mathrm{CQC}^{27}$ state the following: if treatment was carried out using injected local anaesthetic, record:

- Type of drug

- Route of administration

- Volume used

- Manufacturer, batch number and expiry date (however, this may not be recorded in the patients' notes but recorded elsewhere in the practice as part of practice-wide policy on the storage of medicines).

\section{Guidelines, authoritative guidance and} expert opinion straddle the spectrum of evidence-based fact to subjective opinion

Despite there not being any legal or regulatory requirement to record the batch number of each local anaesthetic cartridge when providing dental treatment, Kevin Lewis ${ }^{28}$ records that it has appeared as one of the charges in more than one GDC fitness to practise hearing before the Professional Conduct Committee. This, therefore, is an expected level of compliance with inadequate supporting evidence. This example is consistent with the thrust of Lewis' argument that the level of care and compliance expected of practitioners has risen over the years to levels that are unjustifiable and unreasonable. He asserts, quite rightly, that guidelines and protocols (to which can be added authoritative guidance and expert opinion) straddle the spectrum of evidencebased fact to subjective opinion. Yet, as the scientific evidence pyramid shows, evidence other than that of the highest quality (that is, meta-analysis) should be regarded with caution and any pronouncements based on them should be qualified with should rather than must and allow for a range of interpretations.

\section{Is one form of treatment superior to another?}

If there is little evidence base for many of the procedures that are undertaken in dentistry, it would seem illogical to consider one form of treatment superior to another or to take to task a practitioner who has exercised clinical judgement that falls outside of guidelines. Adhesive bridges (cantilever design) have been an accepted form of treatment to replace missing teeth for many years. What should be the design of the retainer? There are many opinions on this, but the current trend seems to be, for the posterior quadrants, full coverage of the abutment tooth. Departure from this may be considered as not offering the best option to the patient. This is the current teaching in dental schools, directed by the senior academic staff and consultants. These are the people that may be considered to give 'authoritative guidance' as mentioned earlier in the GDC publication and their opinion may well hold sway in a situation where a practitioner's clinical judgement is being scrutinised. The stressful impact of a peer member of the profession giving contrary opinion when engaged in an investigation by the GDC is detailed by Kelleher. ${ }^{25}$ However, a search of the literature reveals that there is no one design that is considered to be superior to another in terms of retention/longevity, also bearing in mind the fallibility of such data. Therefore, the design of the retainer is a matter of clinical opinion and will vary according to the experience of the practitioner as he/she sees appropriate in that particular situation. Criticism of such a design would, therefore, be unjustified if consideration for retention had been incorporated into the design. The question that should be asked is: 'on what basis is the adoption of full coverage now the preferred treatment?' The answer? It seems like a good idea. As with all new treatments, it will have to stand the test of time and until there is evidence that it is superior to any other design it must be left to the individual to treat in what he/she considers as the patient's best interests. It is always easy to be clever after the event! The dental practitioner should feel free to exercise their clinical judgement and not be undermined by expert opinion.

\section{Dentistry is not alone in the weakness of evidence for health interventions}

NHS England is taking action to stop patients undergoing ineffective and risky treatments and states that 'patients would be spared more than 100,000 unnecessary procedures a year. ${ }^{29}$ Seventeen 'common' treatments are now being removed from routine medical/ surgical practice within the NHS after many years of routine application. Robinson ${ }^{30}$ wrote in the British Medical Journal: 'NHS England has identified two categories of interventions it wants defunded. Category 1 procedures have inconclusive evidence of usefulness.' 'It seems sensible not to commission them routinely, says Jonathan Montgomery, Professor of Healthcare Law at University College London. 'There may be evidence that they work unpredictably or are no more likely to work than you'd expect 
randomly. That's not quite the same as saying they don't work at all'. Category 2 procedures should be done only when specific clinical criteria are met. They have 'become habit, and we've lazily carried on despite the evidence,' Montgomery says. 'Putting procedures into this category will force clinicians to think, "does this make sense?"”

$\mathrm{Cobb}^{31}$ in comparing the better surgical outcomes in term of morbidity and mortality for knee joint conditions shows the less invasive procedure to be far more beneficial for the patient. Partial knee replacement is safer, more effective and cheaper. Yet, total knee replacement is still a common procedure. $\mathrm{He}$ surmises that the incentives to undertake the 'big' operation override common sense and rationality. Routine procedures with little or no evidence to justify them? How did they ever become mainstream?

This, together with the comments from Montgomery, should set alarm bells ringing with all dental practitioners as there is little or no evidence for the effectiveness of many of the procedures that we commonly carry out. This neatly explains the variation that we see in the prescription of treatment by dentists, the difficult decisions that often have to be made every day in dental practice to answer the who, how, why, when and where questions about intervention that arise when looking inside a patient's mouth. In practical terms, under the present COVID-19 climate and the tendency to reduce the use of the turbine - the dental equivalent of the 'big' operation of Cobb dentistry too could revisit the justification for the procedures that we undertake and could apply common sense and rationality and go for the smaller, less invasive direct techniques and treatments rather than the more destructive irreversible indirect treatments. However, as a result of this uncertainty over the efficacy of treatments in dentistry, dental practitioners should feel free to exercise their clinical judgement and not be undermined by expert opinion, providing, of course, that they can justify their action.

\section{Conclusion}

Dental professionals should exercise their skills and judgements and not feel that the freedom of the dental professional has been undermined by guidelines, authoritative guidance and expert opinion and the way that these are interpreted by the regulatory bodies. Guidelines, authoritative guidance and expert opinion obviously have an important place in the provision of healthcare but their provenance should be open to question. They should not be regarded as the gold standard, the optimal treatment, in any given situation, without regard to the context of that clinical situation. It is very important that practitioners are aware of the level of care that they should be providing for those that come to them for care and that they feel free to make clinical judgements without the constant fear of unreasonable retribution from third parties such as the GDC or CQC. The tipping point between acceptable and unacceptable behaviour seems solely to lie with such third parties. The boundaries between acceptable and not acceptable, between excellent and good enough and between optimal and suboptimal, because of their subjective nature, are open to different interpretations. The nature of healthcare means that concepts such as judgement, opinion and uncertainty are with us all the time and that we should rely not just on guidelines and expert opinions but on experience too. 'Good judgement comes from experience and a lot of experience comes from bad judgement'. As we progress through our careers, we can reasonably expect the quality of our work and our decision-making to improve. That is not to say that the care we provide soon after graduation is inadequate but to say that, as we progress, we can improve, giving a higher and better level of care. We live in an age where situations are often seen as binary, right or wrong, and not often enough is context taken into account. We should be thoughtful about our practice and continuously learn. We need to be reflective. We should trust our judgement, record it in the patient's notes and be ready to defend it to a third party.

Competing interests

The author declares no competing interests.

\section{References}

1. Merriam-Webster Dictionary. Dentistry. Available at https://www.merriam-webster.com/dictionary/ dentistry (accessed February 2021).

2. Cruess SR, Johnston S, Cruess R L. "Profession": a working definition for medical educators. Teach Learn Med 2004; 16: 74-76.

3. Fish D. Quality mentoring for student teachers: a principled approach to practice. London: David Fulton Publishers, 1995

4. OED Online. Skill. Available at https://www.oed.com/ view/Entry/180865 (accessed March 2021).

5. General Dental Council. Available at https://www. gdc-uk.org (accessed February 2021).

6. General Dental Council. Standards for the Dental Team 2013. Available at https://standards.gdc-uk.org/Assets/ pdf/Standards\%20for\%20the\%20Dental\%20Team.pdf (accessed February 2021).
7. FGDP. Standards in Dentistry. 2nd ed. London: Faculty of General Dental Practice, 2018.

8. OED Online. Good. Available at https://www.oed.com/ view/Entry/79925 (accessed March 2021).

9. OED Online. Quality. Available at https://www.oed. com/view/Entry/155878 (accessed March 2021).

10. Horner K, Eaton K A (eds). Selection Criteria for Dental Radiography. 3rd ed. London: Faculty of General Dental Practice, 2013.

11. Cvar J F, Ryge G. Criteria for the clinical evaluation of dental restorative materials. San Francisco: U. S. Dept. of Health, Education, and Welfare, Public Health Service, National Institutes of Health, Bureau of Health Manpower Education, Division of Dental Health, Dental Health Centre, 1971.

12. Caplin R L. Grey Areas in Restorative Dentistry - don't believe everything you think. London: JandR Books, 2015.

13. Facione N C, Facione P A. Critical Thinking and Clinical Judgement. In Critical Thinking and Clinical Reasoning in the Health Science: A Teaching Anthology. pp 1-13. San Jose: Insight Assessment/The California Press, 2008.

14. Trowbridge R L, Rencic J J, Durning S J. Teaching Clinical Reasoning. Philadelphia, PA: American College of Physicians, 2015.

15. American Philosophical Society. Critical Thinking: A Statement of Expert Consensus for Purposes of Educational Assessment and Instruction. 1990.

16. Frioedemann-Smith C, Drew S, Ziebland S, Nicholson B D. Understanding The Role of GPs' Gut Feelings in Diagnosing Cancer in Primary Care: a systematic review and meta-analysis of existing evidence. Br J Gen Pract 2020; DOI: 10.3399/bjgp20X712301.

17. Stolper $E$, van de Wiel $M$, van Royen $P$, van Bokhoven $M$, van der Weijden T, Dinant $G$ J. Gut feelings as a third track in general practitioners' diagnostic reasoning. J Gen Intern Med 2011; 26: 197-203.

18. NICE. The guidelines manual. 2012. Available at https:// www.nice.org.uk/process/pmg6/resources/theguidelines-manual-pdf-2007970804933 (accessed March 2021).

19. Taylor C. The Use of Clinical Practice Guidelines in Determining Standard of Care. J Leg Med 2014; 35: 273-290.

20. Roulet J-F. How to set up, conduct and report a scientific study. Stomatol Edu J 2017; 4: 90-101.

21. Sequeira-Byron P, Fedorowicz Z, Carter B, Nasser M, Alrowaili E F. Single Crowns or Routine Fillings for the Restoration of Root-Filled Teeth. Cochrane Database Syst Rev 2015; DOI: 10.1002/14651858.CD009109.pub3.

22. Ioannidis J P. Why most published research findings are false. PLoS Med 2005; DOI: 10.1371/journal. pmed.0020124

23. Moonesinghe R, Khoury M J, Janssens A C. Most published research findings are false-but a little replication goes a long way. PLOS Med 2007; DOI: 10.1371/journal.pmed.0040028.

24. Ritchie S. Science Fictions. London: The Bodley Head London, 2020.

25. Kelleher M. The Legal Fallacies about 'if it was not written down it did not happen', coupled with a warning for 'GDC' experts. Br Dent J 2020; 229: 225-229.

26. Dental Protection. Local anaesthetic batch numbers. 2015. Available at https://www.dentalprotection.org/ uk/articles/local-anaesthetic-batch-numbers (accessed February 2021)

27. CQC. Dental mythbuster 8: Dental Care Records. Available at https://www.cqc.org.uk/guidanceproviders/dentists/dental-mythbuster-8-dental-carerecords (accessed February 2021).

28. Lewis K. Professional Standards and Their Escalating Impact Upon The Dental Profession. Br Dent J 2015; 218: 381-383.

29. NHS England. NHS England action to stop patients undergoing ineffective and risky treatments. 2018 Available at https://www.england.nhs.uk/2018/06/ nhs-england-action-to-stop-patients-undergoingineffective-and-risky-treatments/ (accessed February 2021)

30. Robinson A. NHS England's Plan To Pull The Plug On Ineffective Treatments. BMJ 2018; 362: k3028.

31. Cobb J P. Patient safety after partial and total knee replacement. The Lancet 2014; 384 1405-7. DOI: 10.1016/S0140-6736(14)60885-0. 